\title{
Changing the housing environment to reduce obesity in public housing residents: a cluster randomized trial
}

\author{
Deborah J. Bowen ${ }^{1 *}$ D, Lisa M. Quintiliani², Sarah Gees Bhosrekar², Rachel Goodman³ and Eugenia Smith²
}

\begin{abstract}
Background: Public housing residents face significant social, economic, and physical barriers to the practice of health behaviors for prevention of chronic disease. Research shows that public housing residents are more likely to report higher rates of obesity, current smoking, disability, and insufficient physical activity compared to individuals not living in public housing. Because these behaviors and conditions may be shaped by the built and social environments in which they live, we conducted a study to test an environmental level diet and physical activity intervention targeting obesity among urban public housing developments.

Methods: This study was a cluster randomized controlled trial of public housing developments, the unit of analysis and randomization. A total of 10 public housing developments were recruited and subsequently randomized to either receive the intervention package or to serve as comparison sites. The year-long intervention included components to change the dietary and physical activity-related environments of the developments. Surveys at baseline and one-year follow-up provided data on changes in behaviors and weight from participants in both intervention and control developments.
\end{abstract}

Results: Intervention participants significantly changed their eating and activity behaviors and body weight from baseline to one-year follow-up ( $p$ 's <.05) while comparison participants reported no significant changes in any study variable.

Conclusions: These data provide initial support for the idea that interventions targeting the environment of public housing developments can assist residents to change unhealthy behaviors and can possibly reduce the high levels of chronic disease among public housing residents.

\section{Background}

Persons living in public housing report two to three times the rates of chronic disease and related negative health behaviors compared to nonpublic housing residents $[1,2]$. Specifically, obesity (31.0\%), current smoking (34.4\%), and insufficient physical activity (61.8\%) behaviors are all high among public housing residents even when compared to other urban residents [3]. These conditions and behaviors contribute to elevated chronic disease rates in this population [4] and can be targeted for modification through intervention. Therefore, supporting change in these behaviors among this population is an important

\footnotetext{
* Correspondence: dbowen@uw.edu

'University of Washington, 1959 Pacific Street NE, Box 357120, Seattle, WA 98195, USA

Full list of author information is available at the end of the article
}

goal for health promotion efforts among public housing residents.

Given these disparities, the next major question is the choice of intervention strategy or strategies that might be most effective in helping public housing residents to change obesity-related behaviors and reduce chronic disease risk. The approach of multi-level intervention that combine strategies targeted to both individual and environmental levels recognizes the importance of multiple influences on health behaviors. In general, interventions delivered at the individual level, (i.e., those that seek to influence personal factors such as motivation and knowledge and are often delivered one-on-one) produce short-term change, but are not long lasting in the face of an obesogenic environment $[5,6]$. Individual interventions are generally resource intensive, often requiring lots of time and relatively high motivation on the part of the participants. 
Another problem with individual-level interventions that focus on change in individual behaviors, is that they generally elicit low participation rates when offered to the general public [7].

Environmental change might be a reasonable alternative to individual level interventions, in that they take into account social and physical influences on obesity-related behaviors. Investigators have identified multiple areas included below within environments that can serve as intervention targets for change in nonpublic housing settings $[8,9]$. Most urban public housing residents live in city and town neighborhoods where availability of healthy resources within a mile of the housing development is ubiquitous. However, we know from our own previous research that public housing residents prefer to interact with people within their housing development and do not seek intervention opportunities in the neighborhood outside of the development, due to hesitation to use mainstream resources to solve problems $[10,11]$. Thus it is important to target the housing development environment itself. Several aspects of the built environment of public housing developments might also be barriers to engagement in healthy activities, including perceived lack of access to healthful food outlets, food cost, safe physical activity resources [12], and adequate structural facilities within the development such as stairwells and walking paths. All are possible targets for intervention. The relative contribution of each of these environmental elements to poor food choices and sedentary activities is unknown for public housing residents.

Other studies have recruited public housing residents into health behavior change interventions. The Live Well, Viva Bien trial was a group randomized trial among adults in public housing complexes, during which participants received a 12-month environmental level (i.e., mobile fruit $\&$ vegetable markets) and nutrition education intervention to improve fruit and vegetable intake [13]. For smoking, a community health worker led intervention intervened upon public housing residents who smoked to lead them through motivational interviewing-based counseling. At 12-month follow-up, intervention participants $(n=121)$ were more likely than control participants $(n=129)$ to demonstrate 7-day and 30-day point prevalence smoking abstinence (aOR: 2.60 (95\% CI: 1.72-3.94); 2.98 (95\% CI: 1.56-5.68), respectively) [14]. Our own qualitative pilot work $[15,16]$ and those of others [17] suggest public housing residents can identify barriers and facilitators to healthy eating and physical activity and ways to begin to address these obstacles. For instance, 27\% of residents endorsed obesity as a health issue [10]. While these studies establish the feasibility and efficacy potential of interventions conducted in public housing settings, there continues to be a gap in the literature for programs in public housing developments targeting obesity, that have multiple components, and target the environmental level.

\section{Methods \\ Purpose and design}

The design of the study and its intervention have been previously published [18]. Simply, this was a cluster randomized trial, with public housing developments (PHDs) serving as the unit of randomization and analysis. Here we describe the patterns of change in weight, diet behaviors, and physical activity behaviors between baseline and one-year follow-up (12 months after baseline collection) and how these differ between intervention and comparator PHDs.

\section{Participants}

Boston Housing Authority currently houses more than 21,000 people under the public housing program. Boston Housing Authority manages 63 housing developments. Of the 63 developments, 38 are designated as elderly/ disabled developments and 25 are designated as family developments. For this trial, 24 family developments that had 200 or more residents, that were not planning to undergo renovations that would require residents to move, were eligible to participate. Through a process of obtaining approval from development managers and tenant associations [18], we recruited 10 developments (out of 12 approached) to participate in the Healthy Families study; 5 serving as intervention PHDs and 5 serving as control PHDs. PHDs were randomly assigned to either condition, in matched pairs for size of development and existence of health activities in the development. In accordance with our design, all intervention activities were available to all residents in the PHDs randomized to the intervention group. Residents living in PHDs randomized to the control group did not receive any intervention components.

An evaluation cohort was formed in both intervention and control group PHDs that consisted of a group of female residents and their daughters ages 8-15. The evaluation cohort was randomly selected from the overall PHD population in each intervention and control PHD (see Data Collection). Inclusion criteria were: be female; be aged 18-72; live in one of the recruited PHDs and not planning to move for at least 2 years; have responsibility for a girl age 8-15 (also living in the public housing residence), be English or Spanish speaking, and report being willing to make changes to their diet and physical activity habits if desired. Exclusion criteria were: the adult female resident was not able to complete the survey tools or was not interested in participating. The rationale for selecting this population was that female residents represent over $80 \%$ of identified heads of households; furthermore we selected daughters because of the development of obesity during this timeframe 
(8-15 years old). All study materials were available and used in both English and Spanish.

\section{Data collection}

Survey assistants approached randomly selected apartment units within each of the 10 housing developments and requested participation of the adult women in the unit. Using a standardized protocol, survey assistants assessed individual's interest in participating and eligibility. If interested and eligible and willing to participate, the adult female resident provided their written informed consent to participate. Next, following a similar process, their daughters, girls aged $8-15$, gave verbal assent. Initial sample size estimates indicated that a sample of 200 households would provide adequate power for simple main comparisons of body weight. The survey assistant then administered and recorded responses to the baseline survey (see Measures section) for adult participants and measured the women and girl's height and weight. Project staff returned to re-assess the original evaluation cohort 1 year after baseline measurement to repeat the same data collection measures and procedures as at baseline. Survey assistants were not aware of study arm during data collection.

\section{Measures}

Baseline/follow-up survey Measurement difficulties exist for both nutrition and physical activity, and so we used the same strategy to select key single or brief items that have been used before in research studies and compared well with longer measures. Following evidencedbased guidelines for health promotion and weight management, we assessed three nutrition behaviors: fruits and vegetable consumption ("How many servings of fruits and vegetables do you eat each day?" with 12 responses ranging from 0 to 11 or more, which was prefaced with pictures representing portion sizes); [19] soda consumption ("How often do you drink soft drinks or soda pop (regular or diet)?" with 6 responses ranging from never to 2 or more times per day) [20]; mindless eating ("How often do you eat food (meals or snacks) while doing another activity, for example, watching $T V$, working at a computer, reading, driving, playing video games?" with 5 responses ranging from never to always) [20]. We assessed physical activity in the form of walking for leisure, transport, or exercise during the past week with the following question: "During the last 7 days, on how many days did you walk for at least 10 minutes at a time in your neighborhood?" with responses ranging from no walking for more than $10 \mathrm{~min}$ at a time or the option to fill in number of days per week and number of minutes per day [21]. Number of days/week was multiplied by minutes/day to calculate minutes of walking per week. To assess walking behavior, we then asked: "On a typical day how many minutes do you walk in your neighborhood?"; participants filled in the number of minutes per day. Participants also completed standard questions about socio-demographics (age, race/ ethnicity, highest level of education completed, self-rated health), nativity, language spoken at home. To assess self-efficacy to eat more healthfully, we asked "On a scale of 0 to 10, how sure are you that you will eat less sugar and fat during the next year?" with 11 responses ranging from 0 (not sure) to 10 (very sure) [22] (Additional file 1).

Height and weight measurement The survey assistant measured the height and weight (baseline and follow-up) of both the mother and daughter using a scale. This was used to calculate body mass index as the main outcome of the study (BMI, $\mathrm{kg} / \mathrm{m}^{2}$ ). A systematic protocol was used that consisted of the following steps: Survey assistants asked participants remove their shoes and subtracted 3 pounds from the scale measurement to account for clothing weight. Electronic scales were used (Health o Meter, Model HDM770DQ1-05 E097BN Sunbeam Products operating as Jarden Consumer Solutions Boca Raton Florida). The maximum measurement for this electronic scale was 300 pounds. If a resident weighed over 300 pounds, the survey assistants would not take a weight measurement that day. Rather, they would return to the participant's home the following day and weight participants using a second scale (Tanita Body Composition Analyzer, Model TBF-300A Tanita Corporation of America Inc., Arlington Heights, Illinois) that could weigh individuals up to 500 pounds. To measure height, survey assistants taped a tape measure to the wall, asked participants to remove their shoes, and stand with their back facing the wall. Survey assistants then measured height in inches and converted it to inches and feet.

\section{Intervention}

We have previously published the design and conceptual model of our intervention study [16] defined as multilevel: community, organizational, and consumer nutrition and physical activity environments. Residents of intervention PHDs could participate in any of the intervention activities described here. In our first year we focused intervention activities on adult (mothers), with the intention to focus intervention activities for daughters in the second year. However, due to funding cuts, we stopped the project after 1 year.

Lay health advisors Lay health advisors, called Healthy Living Advocates completed a 14-week training in community health outreach, a long-standing program (12+ years) provided by the PHH-PRC $[23,24]$. This program was supplemented by study specific training in which, over 3 days, we trained the Healthy Living Advocates in research processes, study specific intervention activities, and 
weight management information. Topics covered included further training on protecting patient privacy, obesity-related health risks, and ways to encourage weight loss through diet and physical activity behavior change. The Health Living Advocates passed a post-training assessment to demonstrate their knowledge prior to participation in the trial.

Health screenings We offered monthly screenings for blood pressure, smoking, and diabetes risk [25, 26] for residents to learn about their chronic disease risk and receive referrals to a program (such as attending walking groups or cooking demonstrations), to their own health care provider (such as their primary care physician), or given information about how to obtain a provider if they did not have one. Due to the policy landscape at the time of the project, the majority (>95\%) of non-elderly adults in Massachusetts had health insurance, [27] removing this classic barrier to care. The screenings were advertised by the HLAs for 2 weeks before each scheduled screening event. They were $3-4 \mathrm{~h}$ in duration and held in a shared space in the development, were advertised for 2 weeks prior. HLAs attended all screenings to assist with linking residents to the primary care system.

Access to healthy food We selected providing access in the form of a van (Fresh Truck) that sold fruits and vegetables to residents of public housing to provide immediate, affordable, and easy access to healthy food choices $[28,29]$. The van visited each intervention housing development weekly. HLAs at each development promoted the van's offerings and attended the Fresh Truck sessions.

Walking groups Environmental-level barriers to physical activity, particularly among racial/ethnic minority low-income women, have been well documented, including issues with neighborhood safety and lack of places to exercise [30-33]. HLAs were trained as weekly walk group leaders and promoted the groups in the developments via flyers and verbal discussion.

Cooking demonstrations Regular cooking demonstrations offered residents the opportunity to not only obtain nutrition education but also to shape social norms around healthful eating and food preparation practices among friends, family, and neighbors [34-36]. All recipes were tailored to meet the needs of the population both culturally and economically. Demonstrations were held approximately every 3 months per development and were led by a Registered Dietitian. Similar to other intervention activities, HLAs promoted the cooking demonstrations beforehand using flyers and word of mouth. HLAs distributed the included recipes, which focused on foods that were available for purchase from the Fresh Truck, were eligible under the Supplemental Nutrition Assistant Program (SNAP), and/or were approved under the Women, Infants, and Children (WIC) approved.

Resource maps Study staff members created printed maps listing local health-related resources (such as local gyms, walking parks, and places to with healthful eating options) and HLAs handed them out to interested participants at health screenings, food van sessions, walking groups, and cooking demonstrations [11].

Process data Data on indicators of intervention implementation/dosage were collected on three forms (1) Group Activity Form, which gathers information on date, type of event, which development it was held at, which HLA led it, number of attendees, number of steps (if walking group), walk route (if walking group), and participant contact information; (2) HLA Weekly Report, which gathers information on all outreach activities conducted by the HLAs in order to encourage residents to attend intervention events; and (3) Participant Evaluation Form, which gathers information on what participants did and did not like about each of the intervention activities.

\section{Analysis}

Data from the Healthy Family study were collected from PHD respondents nested within PHDs; consequently, all analyses were performed using the PHD as the primary unit of randomization. As the first year of the intervention focused on activities targeted at the adult participants, the current analysis focuses on only the adult data. We first examined the data for differences in key baseline demographic characteristics between study arms, and for differences between dropouts at follow-up vs. those participants that provided data at the 12-month survey, to identify imbalances in the study's sample that could change the interpretation of our data. These analyses were performed using t-tests or chi square tests, as appropriate.

For the main analysis, we examined differences in the changes from baseline to follow-up in the main outcome data between intervention and comparison PHDs. We also calculated differences at the PHD level between intervention and control, and found no differing patterns from the individual-level data. So we report on individual level data for ease of comparison. Linear mixed models were used to evaluate the study's intervention, incorporating the design effects of intraclass correlation within PHD and correlation between the two assessment time points (baseline and follow-up). These regression models incorporated a fixed-effect term for treatment condition along with an adjustment for baseline values for the outcome of interest and a PHD was a random effect to account for clustering within development. Models were fit, adjusting 
for baseline participant level demographic characteristics (age, race, education). There were no baseline patterns of difference in demographic variables, as previously published (18). Data analyses for this paper were generated using SPSS software, version 22. Data were reported using the CONSORT guidelines for reporting [37] (Fig. 1).

\section{Results}

Table 1 presents background variables for the sample of recruited adult participants both overall and by trial arm. Overall, the majority of respondents were Latino (64\%), rely on public health insurance (Medicaid or Medicare) (79\%), and had a high school education or less $(64 \%)$. The follow-up rate from baseline to 12-month follow-up was $72 \%$. There were no significant differences in variables in Table 1 between participants who completed only baseline and participants who completed the follow-up.

\section{Process data}

HLAs were asked to complete forms for specific intervention activities, documenting participation by residents. In total, over 1 year, HLAs documented 12 health screenings (128 total participants, 68 who live in the development), 20 walking groups (62 total participants, 27 who live in the development), and 8 cooking demonstrations (45 total participants, 36 who live in the development). Participants attending activities were also asked to complete a form documenting their perceptions of the activity. For health screenings, 6 evaluation forms from participants were returned; however 51 evaluation forms were returned for walking groups and 37 evaluation forms for cooking demonstrations. Table 2 presents process data for these specific intervention components. As seen in this table, participants who responded considered the intervention useful and the activities achievable. Specifically, both the existence of the activity and the social contact of the activity were seen as helpful by most respondents.

\section{Study outcome data}

The changes in body weight, calculated as Body Mass Index or BMI, for intervention and control participants in the Healthy Families study significantly changed in intervention compared to control groups (Fig. 2). We observed a small but significant difference between intervention and control participants from baseline to follow-up. Intervention participants on average reduced their BMI by 1.5 points (from $30.6(\mathrm{sd}=7.7)$ to $29.1(\mathrm{sd}=10.2))$ while comparison participants increased their BMIs by $0.2 \mathrm{BMI}$ points on average

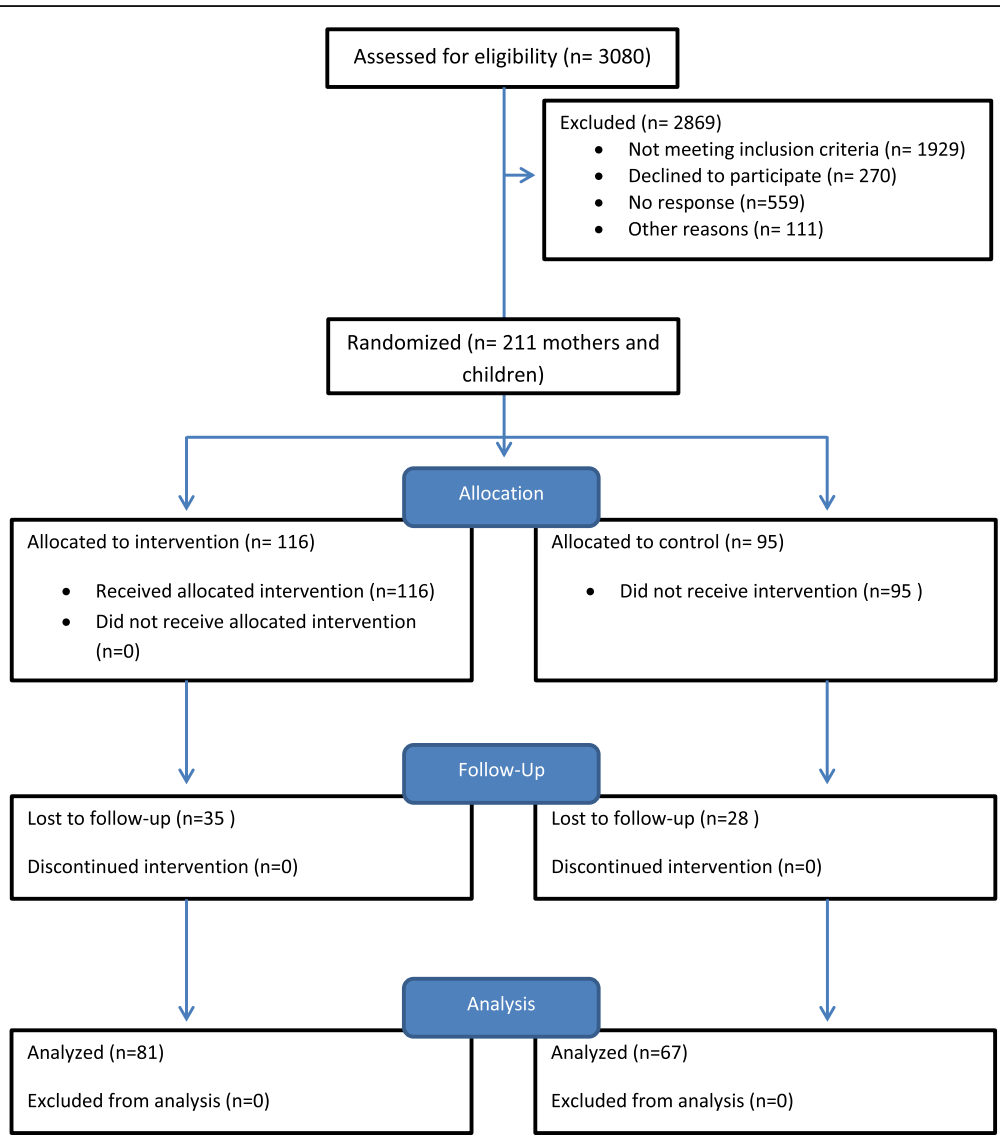

Fig. 1 CONSORT document of the Healthy Families study 
Table 1 Baseline demographic data for participants in the Healthy Families study

\begin{tabular}{|c|c|c|c|}
\hline & $\begin{array}{l}\text { Total }^{a} \\
n=211\end{array}$ & $\begin{array}{l}\text { Control }^{\mathrm{a}} \\
n=95\end{array}$ & $\begin{array}{l}\text { Intervention }^{\mathrm{a}} \\
n=116\end{array}$ \\
\hline Age, years, mean (SD) & $38.1(7.6)$ & $37.1(6.8)$ & $38.8(8.2)$ \\
\hline \multicolumn{4}{|l|}{ Race/Ethnicity ${ }^{b}$} \\
\hline Asian & $3(1.4)$ & $3(3.2)$ & $0(0)$ \\
\hline Black or African American & $50(23.8)$ & $26(27.4)$ & $24(20.7)$ \\
\hline Hispanic/Latino & $134(63.5)$ & $53(55.7)$ & $81(69.8)$ \\
\hline White & $8(3.8)$ & $5(5.3)$ & $3(2.6)$ \\
\hline Other & $10(4.7)$ & $4(4.2)$ & $6(5.2)$ \\
\hline More than one & $6(2.8)$ & $4(4.2)$ & $2(1.7)$ \\
\hline \multicolumn{4}{|l|}{ Language spoken at home } \\
\hline English & $83(39.3)$ & $40(42.1)$ & $43(37.1)$ \\
\hline Spanish & $104(49.3)$ & $38(40)$ & $66(56.9)$ \\
\hline Other & $24(11.4)$ & $17(17.9)$ & $7(6)$ \\
\hline \multicolumn{4}{|l|}{ Born in the U.S. } \\
\hline Yes & $72(34.1)$ & $29(30.5)$ & $43(37.1)$ \\
\hline No & $139(65.9)$ & $66(69.5)$ & $73(62.9)$ \\
\hline \multicolumn{4}{|l|}{ Highest level of education } \\
\hline$<$ High school & $60(28.4)$ & $21(22.1)$ & 39 (33.6) \\
\hline High school graduate/GED & 75 (35.6) & $39(41.1)$ & $36(31.1)$ \\
\hline $\begin{array}{l}\text { Some college or technical } \\
\text { college }\end{array}$ & $48(22.7)$ & $24(25.3)$ & $24(20.7)$ \\
\hline College graduate & $25(11.9)$ & $10(10.5)$ & $15(12.9)$ \\
\hline Other & $3(1.4)$ & $1(1)$ & $2(1.7)$ \\
\hline \multicolumn{4}{|l|}{ Health insurance ${ }^{b}$} \\
\hline Private insurance & $16(7.6)$ & $4(4.2)$ & $12(10.4)$ \\
\hline $\begin{array}{l}\text { Medicaid, MassHealth or } \\
\text { Commonwealth Care }\end{array}$ & $164(77.7)$ & $78(82.1)$ & $86(74.1)$ \\
\hline Medicare & $3(1.4)$ & $1(1)$ & $2(1.7)$ \\
\hline Free care & $10(4.7)$ & $4(4.2)$ & $6(5.2)$ \\
\hline Other & $5(2.4)$ & $5(5.3)$ & $0(0)$ \\
\hline None & $1(0.5)$ & $0(0)$ & $1(0.8)$ \\
\hline More than one & $12(5.7)$ & $3(3.2)$ & $9(7.8)$ \\
\hline \multicolumn{4}{|l|}{ Self-rated health } \\
\hline Excellent & 28 (13.3) & $13(13.7)$ & $15(12.9)$ \\
\hline Very good & $31(14.7)$ & $15(15.8)$ & $16(13.8)$ \\
\hline Good & $86(40.7)$ & $38(40)$ & $48(41.4)$ \\
\hline Fair & $58(27.5)$ & $26(27.4)$ & $32(27.6)$ \\
\hline Poor & $8(3.8)$ & $3(3.1)$ & $5(4.3)$ \\
\hline
\end{tabular}

${ }^{a}$ Numbers represent $\mathrm{n}$

${ }^{\text {b }}$ Subjects were able to choose multiple answers

(from $31.8(\mathrm{sd}=7.7)$ to $32.0(\mathrm{sd}=7.8)$ ). This difference was significant, in both the unadjusted $(p<0.05)$ and adjusted $(p=0.04)$ analyses.

The changes from baseline to follow-up in measured dietary and activity behaviors are presented in Table 3 .
Table 2 Perceptions of residents attending intervention activities: walking groups and cooking demonstrations

\begin{tabular}{|c|c|c|}
\hline & $\begin{array}{l}\text { Walking groups } \\
\text { ( } n=51 \text { forms) }\end{array}$ & $\begin{array}{l}\text { Cooking demonstrations } \\
\text { ( } n=37 \text { forms) }\end{array}$ \\
\hline & $\%$ & $\%$ \\
\hline \multicolumn{3}{|l|}{ Difficulty of activity } \\
\hline Very difficult/difficult & 22 & 3 \\
\hline Neutral & 37 & 3 \\
\hline Easy/very easy & 39 & 92 \\
\hline blank & 2 & 3 \\
\hline \multicolumn{3}{|l|}{ Total time spent on activity } \\
\hline Very difficult/difficult & 20 & 3 \\
\hline Neutral & 39 & 11 \\
\hline Easy/very easy & 39 & 84 \\
\hline blank & 2 & 3 \\
\hline \multicolumn{3}{|l|}{ Usefulness of HLA during activity } \\
\hline Not at all/slightly useful & 0 & 3 \\
\hline Somewhat useful & 4 & 5 \\
\hline Very/extremely useful & 96 & 84 \\
\hline blank & 0 & 8 \\
\hline \multicolumn{3}{|c|}{ Usefulness of fellow activity participants } \\
\hline Not at all/slightly useful & 4 & 3 \\
\hline Somewhat useful & 6 & 0 \\
\hline Very/extremely useful & 90 & 89 \\
\hline Blank & 0 & 8 \\
\hline \multicolumn{3}{|c|}{ Physical benefits from participating in activity } \\
\hline Not at all/slightly useful & 2 & 5 \\
\hline Somewhat useful & 0 & 13 \\
\hline Very/extremely useful & 98 & 76 \\
\hline Blank & 0 & 5 \\
\hline \multicolumn{3}{|c|}{ Social benefits from participating in activity } \\
\hline Not at all/slightly useful & 2 & 3 \\
\hline Somewhat useful & 0 & 0 \\
\hline Very/extremely useful & 96 & 95 \\
\hline Blank & 2 & 3 \\
\hline \multicolumn{3}{|c|}{ Activity makes me want to try new things } \\
\hline Strongly disagree/disagree & 0 & 3 \\
\hline Neutral & 0 & 5 \\
\hline Agree/strongly agree & 100 & 84 \\
\hline Blank & 0 & 8 \\
\hline \multicolumn{3}{|c|}{ Activity will help me control my weight } \\
\hline Strongly disagree/disagree & 0 & 3 \\
\hline Neutral & 2 & 3 \\
\hline Agree/strongly agree & 94 & 92 \\
\hline Blank & 4 & 3 \\
\hline
\end{tabular}




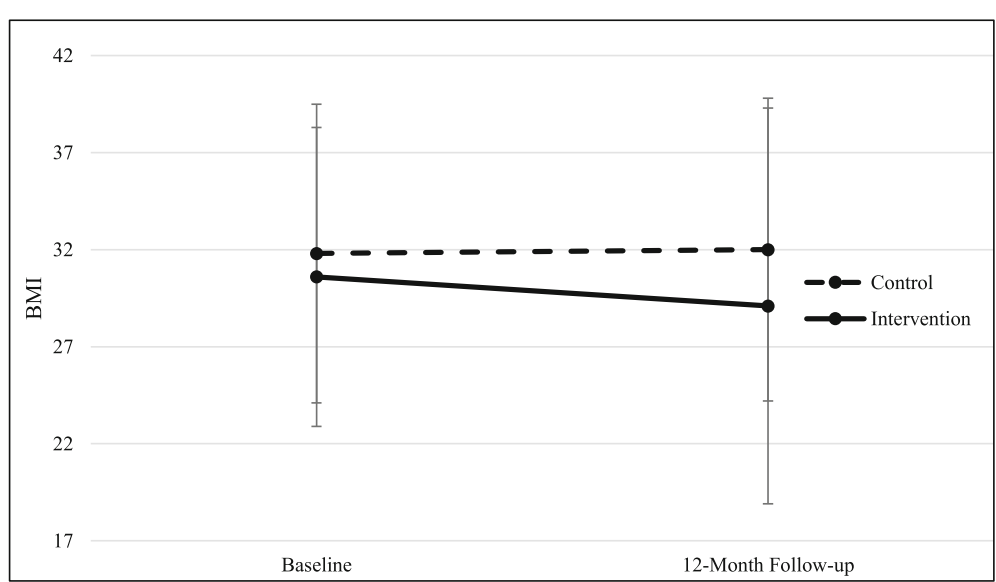

Fig. 2 Body mass Index (BMI) at baseline and 12-month follow-up for participants in intervention and control public housing developments in the Healthy Families study

There were no significant differences between intervention and control participants in any of the baseline values for dietary and activity behaviors. Across the 5 behaviors studied, there were very minimal changes reported by the control participants from baseline to 12-month follow-up, as can be seen in Table 3. In contrast, in four of the five behaviors measured, there were significant improvements from before to after intervention exposure in the intervention participants. Statistically significant change score differences were seen in mean fruit and vegetable intake, in \% of individuals reporting each fast food less than once per week, in the $\%$ of participants reported as inactive, and in minutes of walking in the neighborhood per day (all $p$ values $<0.05$ with paired t-tests or chi square tests as appropriate). Adjustment for baseline value of the outcome variable and for housing development did not alter this pattern of significance in the main outcomes analyzed using multiple regression. The effects of intervention versus control condition was significant in linear regression for both fruit and vegetable consumption $(p=0.03)$ and for minutes per day of walking $(p=0.007)$.

\section{Discussion}

The purpose of this study was to test the effects of an environmental-level package of interventions on public housing residents' obesity and obesity-related behaviors. We aimed to evaluate the effectiveness of a package of intervention opportunities, each element targeting a different aspect of the food and activity environment, on reducing body weight and increasing healthy eating and healthy activity behaviors of public housing residents. We had collected pilot data previously that identified the main barriers and issues that interfered with pursuit of health in these residents. With the guidance of our participating colleagues, we designed an environmentally focused intervention targeting the key behaviors related to obesity. The intervention was successful in reducing weight levels, and in increasing healthy eating (in the form of fruit and vegetable intake and fast food consumption) and healthy

Table 3 Pre- and post-intervention values in obesity-related behaviors among participants in the Healthy Families study

\begin{tabular}{|c|c|c|c|c|c|c|c|}
\hline \multirow[t]{3}{*}{ Variable } & \multicolumn{2}{|l|}{ Baseline } & \multicolumn{2}{|l|}{ Follow-up } & \multicolumn{2}{|c|}{ Change score } & \multirow[t]{3}{*}{ Beta or odds ratio/Adjusted $\mathrm{p}$ value $/ \mathrm{Cl}$} \\
\hline & $\bar{C}$ & 1 & $\bar{C}$ & 1 & $\bar{C}$ & 1 & \\
\hline & $n=95$ & $n=116$ & $n=67$ & $n=81$ & & & \\
\hline Fruits \& vegetables, mean per/day (sd) & $1.9(2.0)$ & $2.0(2.1)$ & $2.0(2.0)$ & $3.6(2.5)$ & +.1 & +1.6 & $2.30 / .03$ \\
\hline Soft drinks, $\%$ once per week or more & $30 \%$ & $31 \%$ & $29 \%$ & $25 \%$ & -1 & -6 & - \\
\hline Fast food, $\%<$ once per week & $66 \%$ & $70 \%$ & $65 \%$ & $55 \%$ & -1 & -15 & $1.7 / .04 / 1.12-3.6$ \\
\hline$\%$ Inactive & $82 \%$ & $89 \%$ & $80 \%$ & $59 \%$ & -2 & -30 & $2.4 / .007 / 1.8-5.6$ \\
\hline Walking in neighborhood, min/day & $19.6(24.6)$ & $19.8(39.8)$ & $19.5(32.2)$ & $30.5(42.7)$ & -.1 & +10.7 & $2.7 / .01$ \\
\hline
\end{tabular}

${ }^{2}$ Adjusted for age, race, education level, baseline value of variable 
physical activity (in the form of walking) over a 12-month period. Four of the five behavioral outcomes were in the hypothesized direction and were consistent in magnitude of change with each other.

From these data we do not have specific explanations as to why this intervention was efficacious. Trials of this design and type are not meant to fully understand which components were the most powerful or useful in producing these changes in the residents. Increased recent attention to trial designs that allow researchers to identify the specific and most active ingredients of change [38] could be applied to the next round of research in this area. This knowledge would help future interventions to be more efficient and potentially increased in potency. Testing multiple components in a fully or partially factorial design would address the issue and would provide much needed knowledge of specific active ingredients.

We ended this study after only 1 year of active intervention and follow-up due to reductions in funding. We originally intended to continue for at least 3 years to enable us to better understand and support sustainability of this type of intervention. We designed the components to be sustainable, together with community partners, but we have no data on the actual events that took place after funding ended. The long-term changes are important to measure and explore, as chronic disease prevention requires changes to occur over years instead of months [39]. Certainly, several of the partners intended to assist with continuing long-term support of healthy behaviors among public housing residents but we do not have data as to their success.

We decided to limit our findings to those data collected from adult participants, and not the daughters, given that the intervention emphasis on daughters was to have happened in the second and third years. Changes in children would be a possible area for future research to pursue. Findings from a survey conducted among public housing communities in Maryland found that the social environment of carers was related to health behaviors among children [40] Future work should aim to more fully incorporate the family unit into intervention delivery activities conducted in public housing.

There were several design choices that limited the generalizability of the study findings. First, the measures of healthy eating and physical activity were relatively minimal. Dietary intake is difficult and time consuming to measure, and so in the interest of minimizing participant burden and increasing total survey completion, we decided to measure key single behaviors related to obesity for which there were existing measures. Measurement of these behaviors is in general complex; there are no brief but perfect measures to use in community-based studies. Still, in future research we must increase attention toward measuring outcomes in a more thorough manner using multiple measures of different inherent biases and shortcomings. We were only able to measure outcomes at baseline and one follow-up, and this limits our understanding of the patterns of change reported by participants. We did not include any objective or observational measures, such as electronic activity monitoring or biomarkers of eating. There are few such biomarkers that track well onto healthy eating, but this is an area for future research as well. We also did not measure any variables that could provide insight into the mechanism of successful changes, although literature on environmental level literature suggests the following variables may have been responsible for these changes. This is a considerable gap, as we now have little idea of why the intervention worked. This too can be rectified in future research projects in public housing.

\section{Additional file}

Additional file 1: PHD survey baseline. This survey was used to collect baseline data for the present study. (DOCX $305 \mathrm{~kb}$ )

\section{Abbreviations}

BHA: Boston Housing Authority; BMl: Body Mass Index; HLA: Healthy Living Advocates; PHD: Public Housing Development; PHH-PRC: Partners in Health and Housing-Prevention Research Center

Funding

This study was funded by a Prevention Research Center grant (CDCU48DP001922). The CDC had no role in the conduct or publication of this manuscript.

Availability of data and materials

The datasets used and/or analyzed during the current study are available from the corresponding author on reasonable request.

\section{Authors' contributions}

DJB led the study, supervised the staff, analyzed the data and drafted the manuscript. LQ conducted several aspects of the intervention, analyzed the baseline data, and assisted with the manuscript. SGB conducted all intervention activities and assisted with data collection. RG contributed to design of the intervention and data collection instruments. Supported data collection and follow-up. ES contributed to design and monitoring of intervention materials and procedures, and provided community leadership and input. All authors read and approved the final manuscript.

\section{Ethics approval and consent to participate}

All adults (18 and over) provided written agreement to participate. All girls aged 8-17 gave verbal assent. We received informed parental consent for the participation of those under the age of 18. This research was approved by the Institutional Review Board of Boston University (FWA00000301).

Consent for publication

Not applicable.

\section{Competing interests}

The authors declare that they have no competing interests.

\section{Publisher's Note}

Springer Nature remains neutral with regard to jurisdictional claims in published maps and institutional affiliations.

\section{Author details}

'University of Washington, 1959 Pacific Street NE, Box 357120, Seattle, WA 98195, USA. Boston University, Boston, USA. ${ }^{3}$ Boston Housing Authority, Boston, USA. 
Received: 25 April 2017 Accepted: 28 June 2018 Published online: 16 July 2018

\section{References}

1. Sobal J, Stunkard A. Socioeconomic-status and obesity - a review of the literature. Psychol Bull. 1989;105:260-75.

2. Ball $K$, Crawford D. Socioeconomic status and weight change in adults: a review. Soc Sci Med. 2005;60:1987-2010.

3. Digenis-Bury EC, Brooks DR, Chen L, Ostrem M, Horsburgh CR. Use of a population-based survey to describe the health of Boston public housing residents. Am J Public Health. 2008;98:85-91.

4. McLaren L. Socioeconomic status and obesity. Epidemiol Rev. 2007;29:29-48.

5. French SA, Story M, Jeffery RW. Environmental influences on eating and physical activity. Annu Rev Public Health. 2001;22:309-35.

6. Whitacre PT, Tsai P, Mulligan J, Rapporteurs; National Research Council. The Public Health Effects of Food Deserts:Workshop Summary: The National Academies Press; 2009.

7. Story M, Kaphingst KM, Robinson-O'Brien R, Glanz K. Creating healthy food and eating environments: policy and environmental approaches. Annu Rev Public Health. 2008:29:253-72.

8. Bowen DJ, Barrington WE, Beresford SAA. Identifying the effects of environmental and policy change interventions on healthy eating. Annu Rev Public Health. 2015;36:289-306

9. Glanz, K., Sallis, J. F., Saelens, B. E. \& Frank, L. D. Healthy nutrition environments: concepts and measures. Am J Health Promot AJHP 19, 330-333, ii (2005).

10. Bowen DJ, et al. What do public housing residents say about their health? Prog Community Health Partnersh-Res Educ Action. 2013;7:39-47.

11. Scammell $M$, et al. Balancing act: approaches to healthy eating and physical activity among Boston Public Housing residents. J Prev Interv Community. 43:109-22.

12. Wilson DK, Van Horn ML, Siceloff ER, Alia KA, St George SM, Lawman HG, Trumpeter NN, Coulon SM, Griffin SF, Wandersman A, Egan B, Colabianchi N, Forthofer M, Gadson B. The results of the "positive action for Today's health" (PATH) trial for increasing walking and physical activity in underserved AfricanAmerican communities. Ann Behav Med. 2015;49(3):398-410. https://doi.org/ 10.1007/s12160-014-9664-1

13. Gans KM, Gorham G, Risica PM, Dulin-Keita A, Dionne L, T G, Peters S, Principato L. A multi-level intervention in subsidized housing sites to increase fruit and vegetable access and intake: rationale, design and methods of the 'Live well, viva Bien' cluster randomized trial. BMC Public Health. 2016:16:521.

14. Brooks DR, Burtner JL, Borrelli B, Heeren TC, Evans T, Davine JA, Greenbaum J, Scarpaci M, Kane J, Rees WW, Geller AC. Twelve-Month Outcomes of a Group-Randomized Community Health Advocate-Led Smoking Cessation Intervention in Public Housing. Nicotine Tob Res. 2017; https://doi.org/10. 1093/ntr/ntx193. Epub ahead of print

15. Scammell MK, Torres S, Wayman J, Greenwood N, Thomas G, Kozlowski L, Bowen D. Balancing act: approaches to healthy eating and physical activity among Boston public housing residents. J Prev Interv Community. 2015:43(2):109-22.

16. Bowen DJ, et al. What do public housing residents say about their health? Prog. Community Health Partnersh. 2013;7:39-47.

17. Rogers C, Johnson J, Nueslein B, Edmunds D, Valdez RS. "I Love Fruit But I Can't Afford It": Using Participatory Action Research to Develop CommunityBased Initiatives to Mitigate Challenges to Chronic Disease Management in an African American Community Living in Public Housing. J Racial Ethn Health Disparities. 2018:12

18. Quintiliani LM, DeBiasse MA, Branco JM, Bhosrekar SG, Rorie JA, Bowen DJ. Enhancing physical and social environments to reduce obesity among public housing residents: rationale, trial design, and baseline data for the healthy families study. Contemp Clin Trials. 2014:39(2):201-10.

19. Peterson KE, et al. Accuracy and precision of two short screeners to assess change in fruit and vegetable consumption among diverse populations participating in health promotion intervention trials. J Nutr. 2008;138:218S-25S.

20. Liebman $\mathrm{M}$, et al. Dietary intake, eating behavior, and physical activityrelated determinants of high body mass index in rural communities in Wyoming, Montana, and Idaho. Int J Obes Relat Metab Disord J Int Assoc Study Obes. 2003;27:684-92.

21. Booth M. Assessment of physical activity: an international perspective. Res $Q$ Exerc Sport. 2000;71:S114-20.
22. Grembowski D, et al. Self-efficacy and health behavior among older adults. J Health Soc Behav. 1993:34:89-104.

23. Rorie J-A, et al. Using resident health advocates to improve public health screening and follow-up among public housing residents, Boston, 2007-2008. Prev. Chronic. Dis. 2011;8:A15.

24. Bowen DJ, Bhosrekar SG, Rorie J, Goodman R, Thomas G, Maxwell N, Smith E. Resident health advocates in public housing family developments. Fam Community Health. 2015;038(2):141-8.

25. Calonge $\mathrm{N}$, et al. Screening for type 2 diabetes mellitus in adults: U.S preventive services task force recommendation statement. Ann Intern Med. 2008:148:846-U63.

26. Kahn $\mathrm{R}$, et al. Age at initiation and frequency of screening to detect type 2 diabetes: a cost-effectiveness analysis. Lancet. 2010;375:1365-74.

27. Long SK, Stockley K, Dahlen H. Massachusetts health reforms: Uninsurance remains low, Self-Reported Health Status Improves As State Prepares To Tackle Costs. Health Aff (Millwood). 2012;31(444-451)

28. Blanck HM, Thompson OM, Nebeling L, Yaroch AL. Improving fruit and vegetable consumption: use of farm-to-consumer venues among US adults. Prev Chronic Dis. 2011:8(2):A49.

29. Widener MJ, Metcalf SS, Bar-Yam Y. Dynamic urban food environments A Temporal Analysis of Access to Healthy Foods. Am J Prev Med. 2011;41:439-41.

30. Brownson RC, Baker EA, Housemann RA, Brennan LK, Bacak SJ. Environmental and policy determinants of physical activity in the United States. Am J Public Health. 2001:91:1995-2003.

31. Eyler AA, et al. Physical activity and minority women: a qualitative study. Health Educ. Behav. 1998:25:640-52.

32. Nies MA, Vollman M, Cook T. African American women's experiences with physical activity in their daily lives. Public Health Nurs Boston Mass. 1999;16:23-31.

33. Bowen D, Rus A, Beltrane C, Drayton M, Williams M, Goodman R. Walking groups: a simple, affordable intervention program for public housing developments. Obesity interventions in underserved communities, V Brennan, S Kumanyika, and Zambrana, (Eds). Blatimore, MD: Johns Hopkins University Press; 2014.

34. Klohe-Lehman DM, et al. Nutrition knowledge is associated with greater weight loss in obese and overweight low-income mothers. J Am Diet Assoc. 2006:106:65-75

35. Cowart LW, et al. Designing and pilot-testing a church-based community program to reduce obesity among African Americans. ABNF J. 2010;21:4-10.

36. Kramer RF, et al. Healthier home food preparation methods and youth and caregiver psychosocial factors are associated with lower BMI in African American youth. J Nutr. 2012;142:948-54.

37. Mohr D, Hayworth S, Schulz KF, Montori V, Goztche PC, Devereauz PJ, Elbourne D, Egger M, Altman DG. CONSORT 2010 explanation and elaboration: updated guidelines for reporting parallel group randomised trials. BMJ. 2010;340:c869.

38. Collins LM, Nahum-Shani I, Almirall D. Optimization of behavioral dynamic treatment regimens based on the sequential, multiple assignment, randomized trial (SMART). Clin Trials. 2014;11:426-34. https://doi.org/10.1177/ 1740774514536795

39. Bauer UE, Briss PA, Goodman RA, Bowman BA. Prevention of chronic disease in the 21st century: elimination of the leading preventable causes of premature death and disability in the USA. Lancet. 2014 Jul 5;384(9937):4552. https://doi.org/10.1016/S0140-6736(14)60648-6

40. Kennedy-Hendricks A, Schwartz H, Thornton RJ, Griffin BA, Green HD, Kennedy DP, Burkhauser S, Pollack CE. Intergenerational Social Networks and Health Behaviors Among Children Living in Public Housing. Am J Public Health. 105:2291-7. 